orbit might (for anything we can say to the contrary) have been beyond the present orhit of Jupiter. However slowly we may suprose the earth to be approaching the sun, yct in the vast epoch of time (which is precisely what is mcessery in order to harmonise with geological evidence) it may have approached railions of miles towards the sun. There is one point of peculiar harmony here which is worth noticing in connection with this, viz., as the sun cools down or gives out less heat to the planets, so the planets reduce their distance from the sun ; thus tending to equalise the heat conditions suitable for life. Thus, although the heat of the sun when first formed may have been enormously greater than it is at present, yet on account of the distance of the planets (including the earth) from it at that remote time, the conditions for life may have been as favourable as now, and thus the first geological changes may have commenced on the earth at that remote epoch when the sun was an incandescent nebula cccupying a vastly greater volume than now (perhaps even the volume of the earth's present urbit), or under these conditions any interval of time for life on the earth that geological evidence may require is afforded.

4. There is another point that would appear to be of interest in connection with this subject. The ratc at which a planet approaches the sun through friction in the media in space would depend (admittedly) on its mass, or would be greater when its mass is less. It follows evidently from this therefore that the great planets, Jupiter, Saturn, \&c.., must have approached the sun at a slower rate than the earth (or the smaller planets generally). It would follow therefore (more particularly in view of the vast epoch of time demanded by geology) that the relative position of the planets must have changed from this cause, that the earth, for example, must at one time have been nearer Jupiter than at present; more especially as the greater velocity of the earth in its present contracted orbit causes greater friction (and thereby brings the earth more rapidly towards the sun). Indeed it is an evident consequence of this principle that it would require only a certain relative diffcrence in mass of the planets (or in the length of the elapsed time) to have made the small planets occupy positions be; ond the larger plarets originally, and so the posicions of the planets to have been reversed, ie., the smaller planets fiurthest from the sun, and the iarger planets nearest. The tendency of the friction evidently is to arrange the positions of the planets, so that the larger are furthest from the sun. ${ }^{1}$ This it may be noted is the position at the present time. We do not of course mean to assume necessarily that there has been an actual reversal in the positinns of the planets; all we adduce is that friction must inevitably tend to shange relative position, when the masses of the bodies are difierent, and whether the positions are reversed depends therefore on the time during which this cause was in operation (and here $w e$ are considering especially the vast interval of time required by geolo:sy)--the change of relative position being more rapid the greater thic relative differences of the masses. Thus it is a known fact that a meteorite approaches the sun or contracts its orbit at an enormously more rapid rate than a planet. It is so far certain that through friction in the medium known to exist in space, the planets (whose masses are different) must have changed to some degree their relative positions, or that the earth (for example) must bave been nearer Jupiter at one time than it is now. These it should be observed cannot be regarded as speculations, but rather as deductions dependent on accepted principles.

5. Time may evidently have as great significance in physical as in geological changes, or in giving time its full import great results may follow; and it will be admitted that it is of interest to trace the slow operation of causes into their legitimate results through lengthened time epochs, not confining the attention to the infinitesimally narrow range of human experience.

London, March 2I

S. TOlVER Preston

\section{English Lake-dwellings and Pile-structures}

General lane Fox has described the old, and, in some cases, successive pile-works in the peat of Finsbury and Southwark, outside Roman London (Anthropological Review, vol. iv. No. 17, April, 1867, pp. lxxi. et seq.). Another very interesting case was evidently under Sir C. Bunbury's observation in 1856 ,

$x$ It would seem a rather curious fact to note that those planets which and win within themselves the greatest store of heat (ie., the large planets), and which therefore would probably be the longest time before they. were adapted to the conditions of life, are those which approach the sun the slowest. It is also evident that the fact of the earth being a small planet whauld tend to augment the difference between the range of .its present, and that of its original, orbit. near Wretham IIall, six miles north of Thetford, where, in a drained mere, "numerous posts of ozk-wood, shaped and pointed by human art, were found standing erect, entircly buried in the peat." Red-deer antlers, both shed and broken from the skull, and also sction off, were found in this peat. (See Onart. Fourn. Gcol. Soc., vol. xii., p. 356.)

Since writing the above, I have been informed that Mr. WV. M. Wylie, F.S.A., referred to this fact in "Archrologia," vol xxxviii., in a note to his excellent memoir on lake-dwellings. I can add, however, that remains of Cervits elaphluts (red deer), C. dama? (fallow deer), Ovis (sheep), Bos lonsifrons (small ox), Sus sirofa (hog), and Canis (dog), were found here, according to information given me by the late C. B. Rose, F.G.S., of Swaffham; who also stater, in a letter dated August Ir, 1856 , that in adjoining meres or sites of ancient meres, as at Saham, Towey, Carbrook, Old Buckenham, and Hargham, cervine remains have been met with: trus at Saham and Towey, Cervus elaphus (red deer); at Buckenham, Bos (ox) and Cervutus capreolus (roebuck); at Hargham, Cervus tarandus (reindeer).

The occurrence of fint implements and flakes in great numbers in the site of a drained lake between Sandhurst and Frimley, described by Capt. C. Cooper King, in the Fournal of the Anthropological Institute, Janıary, 1873, p. 365 , \&c., points also in all probability to some kind of lake-dwelling, though timbers were not discovered.

Lastly, the late Dr. S. Palmer, F.S.A., of Newbury, reported to the "Wiltshire Archrolo ical Society" in I869, that oaken piles and planks had been dug out of boggy ground on Cold Ash Common, near Faircross Pond, not far from Hermitage, Berks. T. RUPERT JONES

\section{Selective Discrimination of Insects}

As bearing on the question discussed by " $\mathrm{S}$. B.," and by Mr. Bridsman and others, at $\mathrm{p} . \mathrm{I}_{3}$ ante, and in previous numbers of NATURE, the following observations may have some interest. One day in the latter part of July, IS77, I took on a flower of red clover (T. fratemse) an humble-hee (Bombisis Carolina?), having the hairs of its body and legs densely dusted with pollen. grains of an Althea, which was in full blossom in the same enclosure, about one hundred feet from the spot where I took the bee.

On the same day and at the same place I attempted to take another Bomlines, which was ravishing a flower of the same species of clover. It escaped me, and, flying to a distance of about twenty feet, alighted on a flower of a Canada thistle (Cirsinzm "ric'nse'), into which it immediately plunged its tongue. After watching it feeci for a moment or iwo, I arain attempted to capture it, when it again escaped, and, flying to about the same distance as before, alighted on a flower of a larkspur (Delphinizum Consolid( $\tau$ ), and upon my third attempt to take it, it flew away and disappeared.

As to whether insects are attracted by odour or colour, I wish to call attention to an observation of Mr. Crouch, as detailed by Mr. Gosse in " $\triangle$ Year at the Shore." "Tealia crassicornis is as good a mimicry of the great dahlias as the Sagartice are of the daisies." "Even bees are occasionally deceived. Mr. Crouch, when once looking at a fine specimen which was expanded so close to the surface that only a thin film of water covered the disc and tentacles, saw a roving bee alight on the tempting surface, evidently mistaking the anemone for a veritable blossom." Covington, Ky., U.S.A.

V. T. C.

\section{The Telephone as a Means of Measuring the Speed of High Breaks}

IN some experiments with an induction coil and wheel break which I have lately been engaged on I have found the telephone useful in determining the number of times per second in which the current is broken.

For this purpose it may be attached to the secondary terminals, or the whole or part of the primary current may be passed through it.

The telephone may also be used generally for determining the speed of electro-magnetic motors by taking advantage of the fact that the current driving them is either short-circuited or broken a definite number of times in each revolution. The telephone wires may in this case be attached at two points some distance apart on one of the battery wires. The note of the telephone gives the number of breaks per second.

Pixholme, Dorking, March 17

J. E. H. GORDON 